\title{
Micro CTD data logger reveals short-term excursions of Japanese sea bass from seawater to freshwater
}

\author{
Naoyuki Miyata ${ }^{1, *}$, Tomohiko Mori ${ }^{1}$, Masaaki Kagehira ${ }^{2}$, Nobuyuki Miyazaki ${ }^{3}$, \\ Michihiko Suzuki ${ }^{4}$, Katsufumi Sato ${ }^{1}$ \\ ${ }^{1}$ Atmosphere and Ocean Research Institute, The University of Tokyo, 5-1-5 Kashiwanoha, Kashiwa, Chiba, 277-8564, Japan \\ ${ }^{2}$ Oita Prefecture Southern Region Bureau Rural Community Promotion Department, Saiki, Oita, 876-0813, Japan \\ ${ }^{3}$ Japan Marine Science Foundation, Taito, Tokyo, 110-0008, Japan \\ ${ }^{4}$ Little Leonardo, Bunkyo, Tokyo, 113-0021, Japan
}

\begin{abstract}
We conducted calibration tests and field deployments of a newly developed micro CTD data logger on Japanese sea bass Lateolabrax japonicus to measure fine-scale movement and reconstruct micro-salinity profiles of estuarine habitat. In June, July and November 2013 and 2014, Japanese sea bass were caught in the Ohno $\left(33^{\circ} 12^{\prime} \mathrm{N}, 131^{\circ} 36^{\prime} \mathrm{E}\right)$ and Oita $\left(33^{\circ} 16^{\prime} \mathrm{N}, 131^{\circ} 41^{\prime} \mathrm{E}\right)$ Rivers in Oita Prefecture, Japan. In seawater tanks, the measurement drift for salinity was negligible over a $2 \mathrm{wk}$ period $(\mathrm{n}=8)$. Moreover, in the estuary, the values of standard seawater measured at pre- and post-deployment of sensors on fish were consistent to the first decimal place; therefore, sensor drift was negligible ( $\mathrm{n}=4$, duration: 53-129 h). In situ measurements of depth, temperature, and salinity (conductivity) successfully revealed the microenvironment, and showed that Japanese sea bass often ascended from deep seawater to shallow freshwater at night. In all fish, over $99 \%$ of these excursions were completed within $10 \mathrm{~min}$. The maximum duration of these excursions was about $6 \mathrm{~h}$. This might be an effective strategy for temporal utilization of hypo-osmotic environments for foraging without physiological and energetic costs. This is the first report to clearly validate the accuracy of salinity measurement without sensor drift in free-ranging fish. The device and methods presented here can be applied to other euryhaline fish.
\end{abstract}

KEY WORDS: Bio-logging $\cdot$ Estuary $\cdot$ Euryhaline fish $\cdot$ Osmoregulation $\cdot$ Salinity

\section{INTRODUCTION}

Estuaries rank among the most biologically productive ecosystems on Earth (Pinet 2011). Hence, estuarine fishes are typically abundant but represent relatively few species, largely because of the dynamic nature of their environment (Pinet 2011). One of the most variable characteristics of estuarine water is salinity, which is controlled by river inflow, tides, rainfall etc. Thus, salinity is an important variable in investigations of the behavioral ecology of estuarine fish. Salinity may act directly or indirectly in control-

${ }^{*}$ Corresponding author: nao.miyata@gmail.com ling the distribution of estuarine-dependent fish (Bulger et al. 1993, Lankford \& Targett 1994). Spatial behaviors may also be affected by the distribution of predators and prey within estuaries, both of which are affected by salinity (Boesch 1977, Weinstein et al. 1980, Currin et al. 1984, Lankford \& Targett 1994). Water salinity directly affects physiological processes such as osmoregulation, respiration, metabolism, and growth (Plaut 1999, Bœuf \& Payan 2001, Tseng \& Hwang 2008, Takei et al. 2014). Physiologically, estuarine-dependent fish are expected to be able to cope with the large salinity changes that occur in

() The authors 2016. Open Access under Creative Commons by Attribution Licence. Use, distribution and reproduction are unrestricted. Authors and original publication must be credited. 
estuaries. It is widely accepted that catadromous, anadromous, amphidromous, and other estuarine species are euryhaline organisms (Zydlewski \& Wilkie 2012). Members of the diadromous group have the ability to switch their osmoregulatory mechanisms as they migrate from freshwater to seawater or vice versa (Zydlewski \& Wilkie 2012); however, these mechanisms come with physiological and energetic costs. Detailed salinity information is required to reveal the habitat use and the reaction to salinity variation of estuarine fish on tidal and daily time scales.

In recent years, telemetry and bio-logging devices have produced large amounts of data on marine animals (Fedak 2004) at fine temporal and spatial resolutions. While depth and temperature sensors are relatively stable, methods used to measure conductivity in order to calculate salinity have presented great challenges (Fedak 2004). In several research projects, data loggers deployed on marine mammals were successfully used to collect salinity data measurements (Lydersen et al. 2002, Hooker \& Boyd 2003, Biuw et al. 2007, Boehme et al. 2008a,b, Charrassin et al. 2008, Roquet et al. 2009, Meredith et al. 2011). However, the large size of the loggers (545 $\pm 5 \mathrm{~g}$ in air; see Boehme et al. 2009 for detailed specifications) means they are only suitable for use with relatively large organisms. One small conductivity logger using a 2-AC bipolar sensor is commercially available (DST CTD, Star-Oddi) and has been used to investigate the migration patterns of Atlantic salmon Salmo salar L. and sea trout Salmo trutta L. (Sturlaugsson \& Sigmar 1997). Bipolar sensors can be affected by erosion and fouling because the metal electrodes are directly exposed to the water. Furthermore, measurements are affected by the proximity of other objects (nearfield effect), since the sensor measures conductivity by generating an electromagnetic field around the electrodes. To date, there have been no studies that test the accuracy of salinity measurements using 2-AC bipolar sensors, although these may be affected by drift over time and the near-field effect.

In this study, we conducted calibration tests and initial field deployments using a new micro-salinity data logger (ORI400-DTC, Little Leonardo) on Japanese sea bass Lateolabrax japonicus to measure finescale sea bass movement and reconstruct the microsalinity of their estuarine habitat. Japanese sea bass are euryhaline marine fish inhabiting coastal areas and estuaries in Japan, occasionally appearing in freshwater (Ochiai \& Tanaka 1998). The migration patterns of larval and juvenile Japanese sea bass have previously been investigated and amphidromous characteristics have been found in some popu-

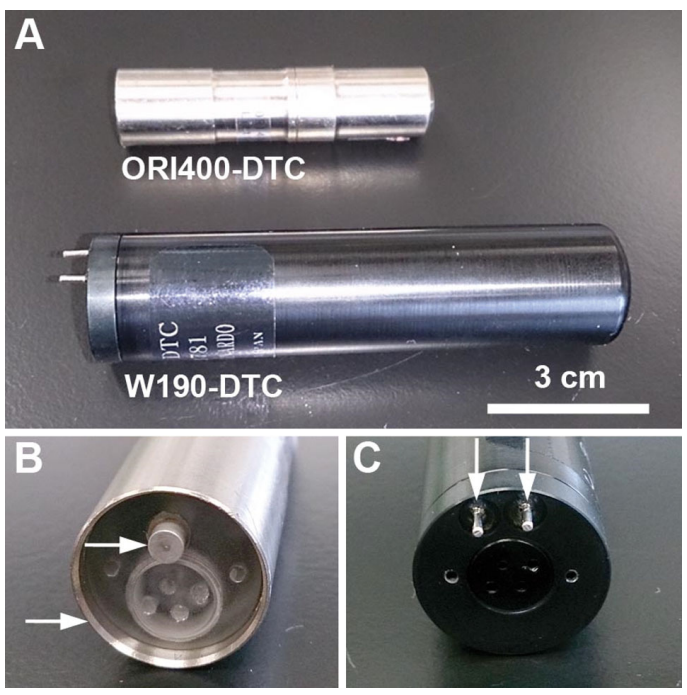

Fig. 1. Two types of salinity data logger and design of conductivity sensor. (A) Comparison of sizes. (B) Sensor design of ORI400-DTC, which measures the current between the titanium pole and cylinder body. (C) Sensor design of the W190-DTC, which uses 2 stainless steel poles. This is used as control for comparison with the improved model (ORI400DTC). Arrows indicate electrodes

lations (Tanaka 1997), with fish immigrating to freshwater at the larva-juvenile transformation phase or early juvenile stage. There are few reports of adult fish migration; however, catches have been reported in the upper reaches of inland rivers (Shoji et al. 2002). According to local anglers, some populations of adult fish seasonally travel up rivers, following baitfish.

\section{MATERIALS AND METHODS}

\section{Data loggers}

We used 2 types of data loggers to record depth, temperature, and conductivity experienced by Japanese sea bass. (ORI400-DTC and W190-DTC, Little Leonardo: $14 \mathrm{~mm}$ diameter, $58 \mathrm{~mm}$ length, $19 \mathrm{~g}$ in air and $19 \mathrm{~mm}$ diameter, $90 \mathrm{~mm}$ length, $45 \mathrm{~g}$ in air, respectively; Fig. 1). The 2-AC bipolar sensor was applied to these data loggers. ORI400-DTC measures conductivity between the cylindrical body and a pole made of titanium, and W190-DTC measures conductivity between 2 stainless steel poles. We used an older model (W190-DTC) as a control to compare measurement drift of salinity with that of the improved model, ORI400-DTC. Therefore, only the specifications of ORI400-DTC are shown (Table 1). Measured conductivity was converted to salinity using software (Salin- 
Table 1. Specifications of the ORI400-DTC data logger. Time constant represents the time required to reach $63.2 \%$ of its final value following a sudden water condition change from one stable condition to another. Values in parentheses are the ranges in which accuracy was guaranteed

\begin{tabular}{|lccc|}
\hline & Depth $(\mathrm{m})$ & Temperature $\left({ }^{\circ} \mathrm{C}\right)$ & Salinity \\
\hline Range & $0-400$ & -10 to 50 & $0-40$ \\
Resolution & 0.2 & 0.1 & 0.5 \\
Accuracy & $\pm 2(0-100)$ & \pm 0.5 & $\pm 1.5(0-35)$ \\
Time constant $(\mathrm{s})$ & $\pm 2 \%(100-400)$ & $<15$ & - \\
\hline
\end{tabular}

ity Logger Tools, Little Leonardo), according to the Practical Salinity Scale of 1978 (UNESCO 1981). The duration of recording ranged from 40 to $300 \mathrm{~d}$, depending on the sampling interval of the data logger (1-60 s).

\section{Calibration experiments}

The day before the calibration experiments took place, the data loggers were activated and the surfaces of the electrodes were wiped with $99 \%$ ethanol and then brushed with a cotton swab soaked in flux (SUSSOL-F, Hakko) to remove any oxide coating. The data loggers were then soaked in seawater for over $24 \mathrm{~h}$ at room temperature to make the oxide film stable underwater.

Accuracy tests of the ORI400-DTC were conducted in plastic (polyethylene) buckets containing water of various salinities $(0,7.0,13.9,21.0,27.6$, and 34.8). The salinity of water from each bucket was measured using the ORI400-DTC and a conventional CTD profiler (Compact-CTD Lite, JFE Advantech, accuracy \pm 0.03). Using the ORI-400DTC, the seawater in the buckets was tested for a near-field effect at various distances $(0.0 .5,1.0,2.0,3.0,4.0$, and $5.0 \mathrm{~cm})$ from the polyethylene. According to Hooker \& Boyd (2003), polyethylene negatively affected salinity measurements more than wood or nylon carpet. Different sensor angles were also tested. To check measurement drift, the data loggers, which had been prepared as described above, were soaked in aerated seawater at $15^{\circ} \mathrm{C}$. The salinity of standard seawater, (with a constant salinity of 34 ) stored in sealed containers, was measured every other day over 2 wk. Drift was represented by the difference between measurements made using the data loggers (ORI400DTC and W190-DTC) and those using the conventional CTD profiler. After each test, measurements of data loggers were uploaded to a $\mathrm{PC}$, and the data were calibrated using the software.

\section{Field experiments}

The field study procedures were approved by the ethics committee at the University of Tokyo (Institutional Animal Care and Use Committee Protocol P1214, P13-11).

In the field experiments, only the new smaller data logger (ORI400-DTC) was tested. Before the data loggers were attached to the fish, we measured standard seawater (salinity: 34.0, measured using a conventional CTD) as a reference for salinity calibration. In June, July and November 2013 and 2014, a total of 9 Japanese sea bass Lateolabrax japonicus were caught by lure fishing in the Ohno and Oita Rivers in Oita Prefecture $\left(33^{\circ} 12^{\prime} \mathrm{N}\right.$, $131^{\circ} 36^{\prime} \mathrm{E}$ and $33^{\circ} 16^{\prime} \mathrm{N}, 131^{\circ} 41^{\prime} \mathrm{E}$, respectively), Japan. The fish were first anaesthetized using 1/5000 2-phenoxyethanol. Using a needle, 2 small holes were made in the dorsal musculature in front of their dorsal fin. Two plastic cable ties were then passed through the holes to fix a plastic mesh in place. A tag consisting of the data logger (ORI400-DTC), the VHF transmitter (MM130B, Advanced Telemetry Systems; $16 \mathrm{~mm}$ diameter, $60 \mathrm{~mm}$ length, and $20 \mathrm{~g}$ in air), a time-release mechanism (RT-4, Little Leonardo; 16 $\mathrm{mm}$ diameter, $25 \mathrm{~mm}$ length, and $16 \mathrm{~g}$ in air), and a float were attached to the plastic mesh. After recovery from anesthesia, fish were released in the same location in which they were caught. Tags automatically detached from each fish using a time-scheduled release system. After detachment, the floating tags were located using the VHF signals they transmitted and were retrieved by a boat.

To check the validity of the salinity and temperature profiles estimated from the fish-borne data loggers, we performed a series of relatively short tagging experiments in 2013 (deployment duration: $1-2 h_{i} \mathrm{n}=5$ fish, total length: $480-825 \mathrm{~mm}$, body mass: $0.83-3.97 \mathrm{~kg}$ ). After the fish had been released, the water column was measured by conventional CTD at the point of release. To investigate fish behavior and habitat use, we conducted longer deployments in November 2014 (deployment duration: 53-158 $\mathrm{h}$; $\mathrm{n}=4$ fish, total length: $488-775 \mathrm{~mm}$, body mass: $0.88-4.94 \mathrm{~kg}$ ). After retrieval of the data loggers, we again measured the same standard seawater used for the pre-deployment salinity measurement to assess instrument drift, which can be caused by sensor erosion and fouling in the natural environment. Exposure to air was kept to under $1 \mathrm{~h}$ to preserve sensor surface conditions. 


\section{Data analysis}

To visualize the thermal and salinity structure surrounding the tagged fish, (1) a temperature-at-depth and salinity-at-depth matrix with $1 \mathrm{~h}$ time bins was constructed by calculating the average temperature and salinity at each depth value within each time bin (fish profiles), and (2) the isotherm and isohaline were constructed based on the resulting temperaturedepth and salinity-depth field (Watson \& Merriam 1992). In the short tagging experiment, the data for the first hour of fish profiles were compared with those of the CTD profiler. In the longer experiment, original depth data of where the fish swam were averaged with 1-h time bins, and the result was plotted in the salinity structure. Temperature and salinity data obtained by fish-borne data loggers were analyzed using Igor Pro (Wave metrics). To estimate the impact of ambient water salinity on fish physiology, we used a threshold salinity of 12 , which has roughly the same osmolality as the body fluid of teleost fish, to distinguish between different behavioral responses.

\section{RESULTS}

\section{Calibration of data loggers}

Salinity measurements taken by the ORI400-DTC in all 6 water tanks (salinity: 0, 7.0, 13.9, 21.0, 27.6, and 34.8) were accurate to within 1.5 of measurements by conventional CTD profilers, and the precision of the data loggers was \pm 0.3 . As expected, the near-field effect on the conductivity sensor (a titanium pole) was pronounced when the obstacle (polyethylene) was immediately adjacent to the titanium pole of the loggers, and the effects were negligible when the distance between obstacle and titanium pole was $>1 \mathrm{~cm}$ (Fig. 2A,B). The angle of the titanium pole relative to the obstacle also affected salinity measurements (Fig. 2C). These results suggest that when the data loggers (ORI400-DTC) are attached to animals, the titanium pole should be kept at sufficient distance (we suggest at least $1 \mathrm{~cm}$ ) from the fish's body. If other instruments are deployed on the same fish, and these instruments have to be fixed to each other, salinity calibration must be done in a fixed setting without any obstacles within a $1 \mathrm{~cm}$ radius of the titanium pole. In our field study, we used a VHF transmitter, float, and a time-release mechanism to retrieve the data loggers; we fixed them to each other and performed calibration under the same conditions (Fig. 3). Accuracy and precision
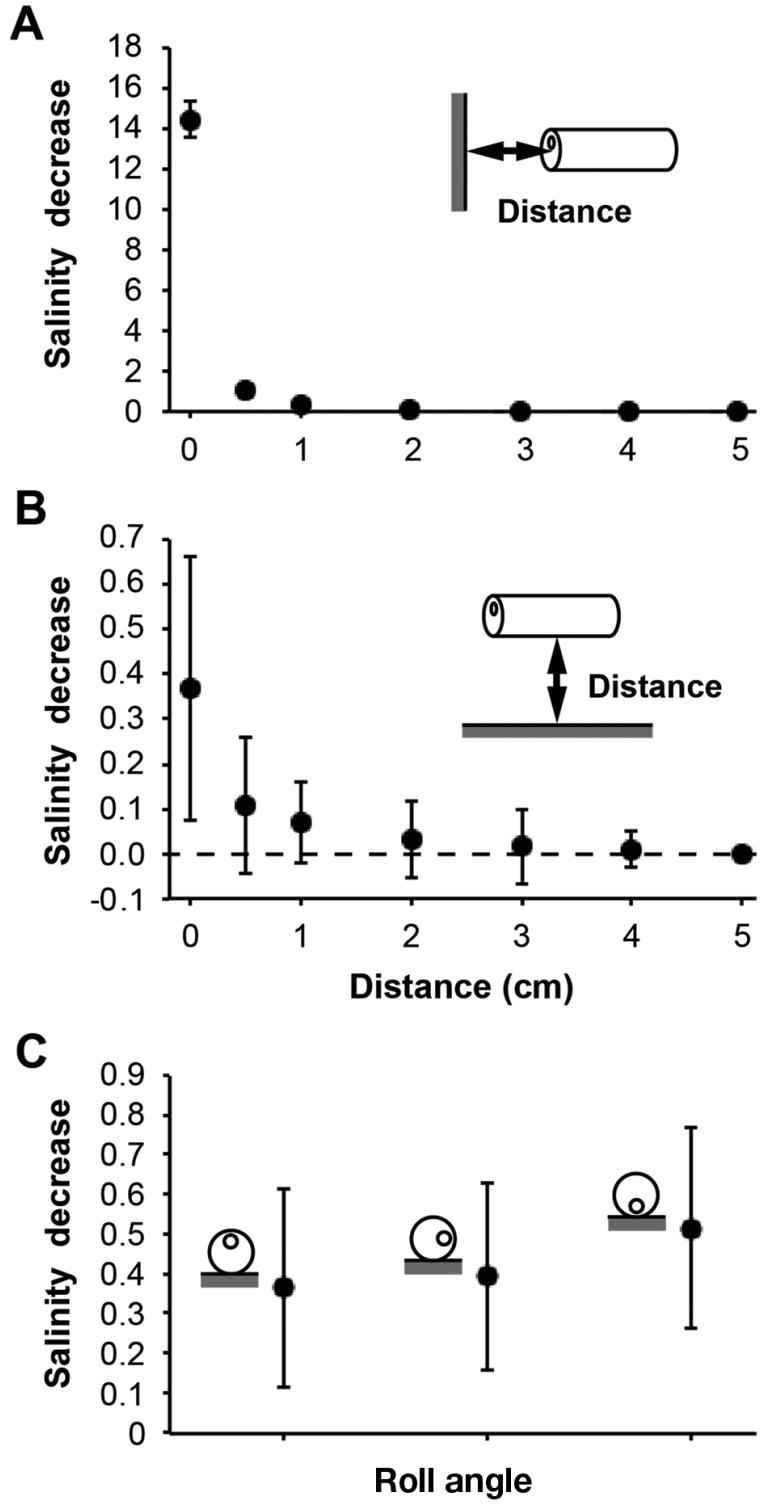

Fig. 2. Near-field effect of the obstacle (polyethylene) on the conductivity sensor (ORI400-DTC). (A) Longitudinal distance between the logger and the obstacle, (B) distance in dorsoventral axis direction, and (C) roll angle of sensor relative to obstacle. Data are means $\pm \mathrm{SD}(\mathrm{n}=8)$

did not differ from the values mentioned at the beginning of this paragraph.

Fig. 4 shows the drift of salinity measurements recorded by 2 types of data loggers soaked in aerated seawater for $2 \mathrm{wk}$. The measurement drift for the ORI400-DTC salinity readings, which measured the current between the titanium pole and cylinder body, was $\leq 1$ throughout the experiment. This stability was better than that for W190-DTC, which used 2 stainless steel poles. In both types, significant variation of salinity values occurred within the first $2 \mathrm{~d}$. These 

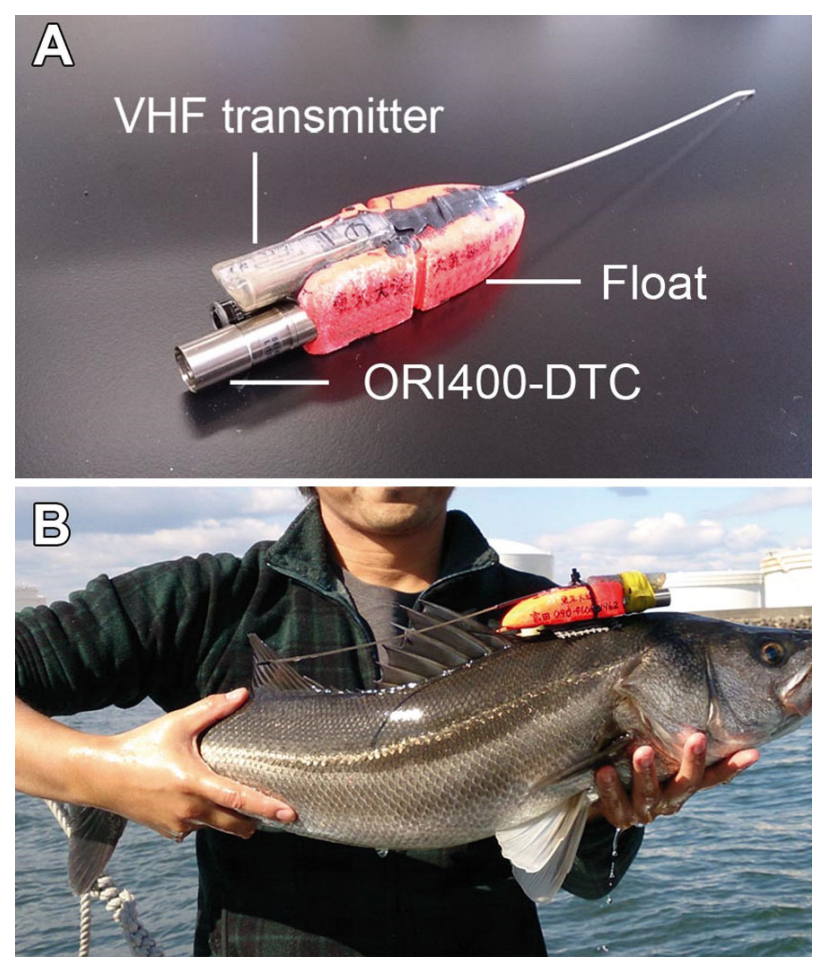

Fig. 3. (A) A tag consisting of the data logger (ORI400-DTC), VHF transmitter and float. (B) The tag was attached in front of the dorsal fin of Japanese fish bass.

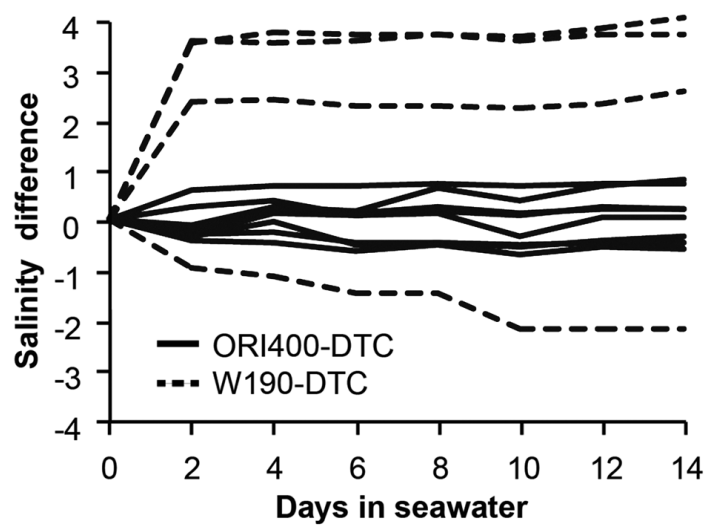

Fig. 4. Salinity measurement drift in seawater for the 2 data logger types ORI400-DTC ( $=8)$ and W190-DTC ( $=4)$. The data loggers were soaked in aerated seawater for $14 \mathrm{~d}$ at $15^{\circ} \mathrm{C}$ after calibration, and measured in standard seawater every second day

results indicate that the ORI400-DTC can provide reliable salinity readings over several weeks. They also indicate that the reliability of the measurements may have been improved by the pre-conditioning procedure in which the data loggers were soaked in seawater (we recommend $>3$ d) before being attached to the fish.

\section{Field experiments}

When the fish remained in a stable environment $(\mathrm{n}=4$; Fig. 5A,C), fish profiles coincided well with vertical profiles measured by a conventional CTD profiler lowered manually into the water column, and measurement error was negligible even in the nonaveraged original data. On the other hand, when fish experienced a wide range of salinity levels around the mouth of the river $(n=1$, Fig. $5 B$ ), original data from fish-borne loggers varied widely. However, averaged fish profiles coincided well with CTD profiles.

For longer measurements made in natural habitats $(\mathrm{n}=4,53-158 \mathrm{~h})$, salinity values of standard seawater measured pre- and post-deployment were consistent to the first decimal place (Table 2). This result indicates that the erosion and fouling effects on the conductivity sensor were negligible in this experiment. Three fish were caught in a freshwater area and the other fish were caught in a seawater area (Fig. 6A). All fish experienced a wide range of salinity that was in the same range when swimming from seawater to freshwater; however, mean salinity ranged from 13.9 to 32.9 (Fig. 6B). All of the mean values were above one-third of the salinity of seawater.

When we analyzed salinity data with a resolution of $1 \mathrm{~h}$, we found that fish often ascended to shallow water with low salinity at night (Fig. 7). When we examined data at a more detailed time scale (sampling interval: $1 \mathrm{~s}$ ), the duration of each freshwater (FW) excursion, in which fish were in lower osmotic water than body fluid (defined salinity $<12$ ), was found to be $<1 \mathrm{~h}$ in 3 of 4 fish and $<6 \mathrm{~h}$ in the other fish (Fig. 8). In total, over $99 \%$ of FW excursions were finished within $10 \mathrm{~min}$ (fish1: 100.0\%, fish2: 99.7\%, fish3: 99.4\%, fish4: 99.0\%).

\section{DISCUSSION}

\section{Micro CTD data logger}

The results of this study indicate that a newly developed CTD data logger (ORI400-DTC) can successfully measure micro variations in the salinity levels of the habitat surrounding a mid-sized predator, the Japanese sea bass. This is the first report which clearly validates the accuracy of salinity measurement without sensor drift in free-ranging fish, as the measurement drifts were negligible over several days. As is the case with drifter buoys, salinity (conductivity) sensor fouling is a problem with animalborne data loggers, although maybe less of a prob- 

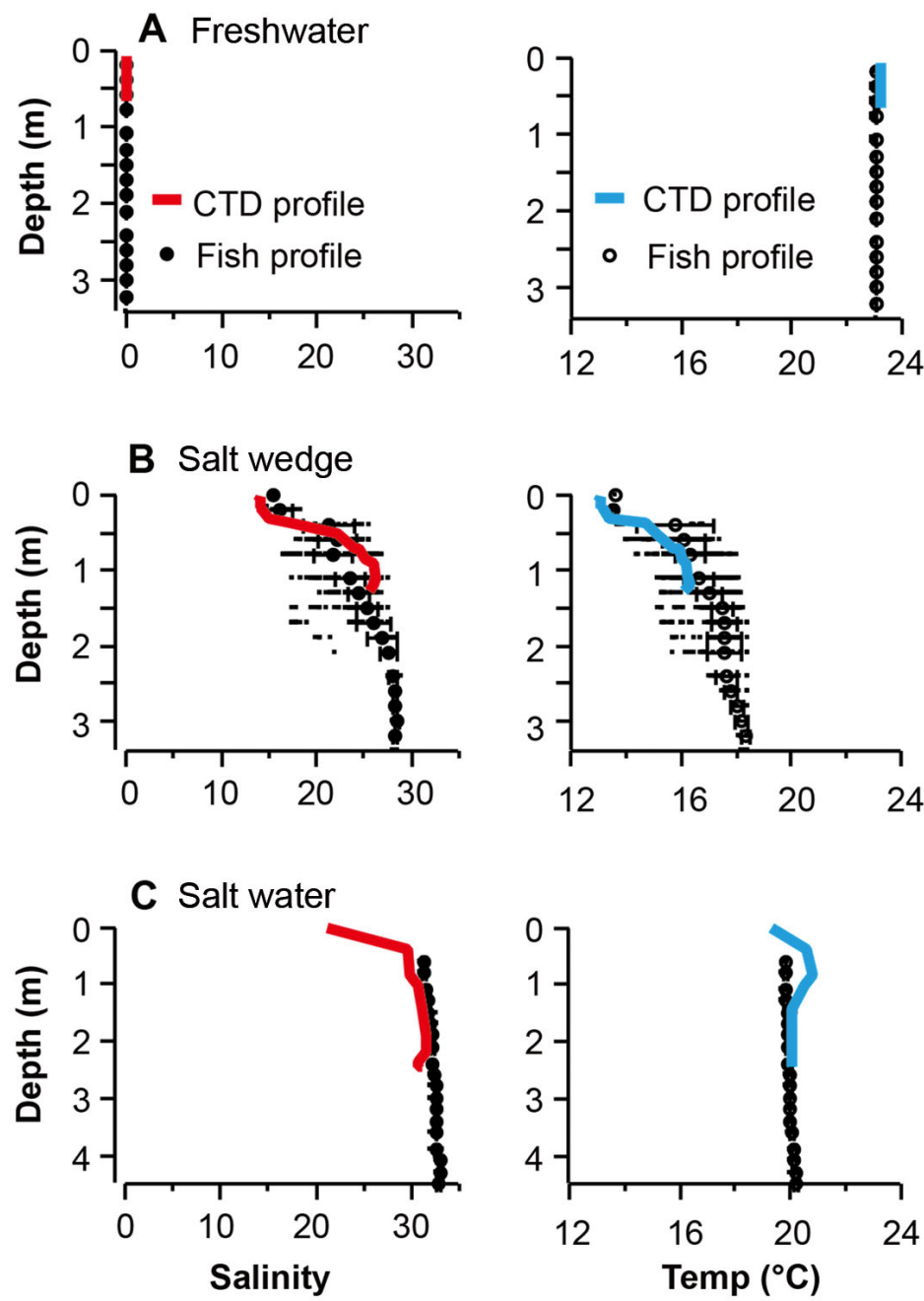

Fig. 5. Comparison of vertical profiles of salinity and temperature measured by a conventional CTD and a fish-borne data logger $(\mathrm{n}=3)$. Red and blue lines represent vertical profiles of salinity and temperature, respectively, measured by a conventional CTD profiler in (A) a freshwater area, (B) a salt wedge area; in which salinity change is $>10$ between surface and bottom and (C) a seawater area. Filled and open circles represent averaged data calculated from $1 \mathrm{~h}$ data sets from fish-borne data loggers (fish profiles), error bars represent SD, and dots indicate original $1 \mathrm{~h}$ data

Table 2. Salinity measurement drift in standard seawater, as measured by CTD data logger (ORI400-DTC), between pre- and post-deployment on fish. Values are means \pm SEM

\begin{tabular}{|lccc|}
\hline ID & \multicolumn{3}{c|}{ Salinity of standard seawater } \\
& $\begin{array}{c}\text { Pre- } \\
\text { Peployment }\end{array}$ & $\begin{array}{c}\text { Deployment } \\
\text { deployment }\end{array}$ & duration (h) \\
\hline Fish1 & $34.0 \pm 0.0$ & $34.0 \pm 0.0$ & 129 \\
Fish2 & $34.0 \pm 0.1$ & $34.0 \pm 0.1$ & 109 \\
Fish3 & $34.0 \pm 0.0$ & $34.0 \pm 0.0$ & 158 \\
Fish4 & $34.0 \pm 0.0$ & $34.0 \pm 0.0$ & 53 \\
\hline
\end{tabular}

lem because of the animals' continuous movement through the water (Fedak 2004). This problem is greater when using a 2-AC bipolar sensor than an inductive conductivity sensor because the metal electrodes are directly exposed to water. We resolved this problem by using sensor electrodes made of stable titanium and by pre-conditioning the sensor electrodes.

Fine-scale and direct measurement of salinity surrounding aquatic organisms is considerably more difficult using the other conventional methods. Recently, many studies of anadromous and catadromous fish migration in estuarine habitats have been made easier by measuring the strontium ( $\mathrm{Sr}$ ) concentration in the otoliths, because $\mathrm{Sr}$ is generally recognized as a proxy of water salinity (Elsdon \& Gillanders 2003, Gillanders 2005, Reis-Santos et al. 2013). However, this method has 2 limitations. Firstly, use of otoliths requires killing the individual. Secondly, in practice, the assay and interpretation of this chemical record is less than clear-cut, in part due to physiological filters between the ambient water and the otolith (Kalish 1989). Therefore, it is also unlikely that otolith chemistry would reveal short-term excursions into freshwater such as those observed in the present study. The data logger used in the present study directly measures ambient water at a fine scale. Therefore, data loggers can play a significant role in revealing the habitat use and the reaction to micro-salinity habitat variation of estuarine fish at tidal and daily time scales.

This new data logger and the methods presented here for Japanese sea bass can also be applied to other fish inhabiting estuaries. However, 2 issues should be considered when applying this method to fish research: (1) the near-field effect and (2) measurement error caused by the slow response time of the temperature sensor. The near-field effect was reduced to a negligible level by fixing instruments to each other and creating a space around the conductivity sensor. Nevertheless, the proximity of a sensor on a fish to any inorganic and organic materials, such as rocks, seaweeds and sea grasses occurring in the fish's habitat, can result in temporary errors. When reconstructing the environment from information from an animalborne data logger, the sensor response time affects the resulting profiles. Previous studies have thus attempted to estimate the true temperature from meas- 

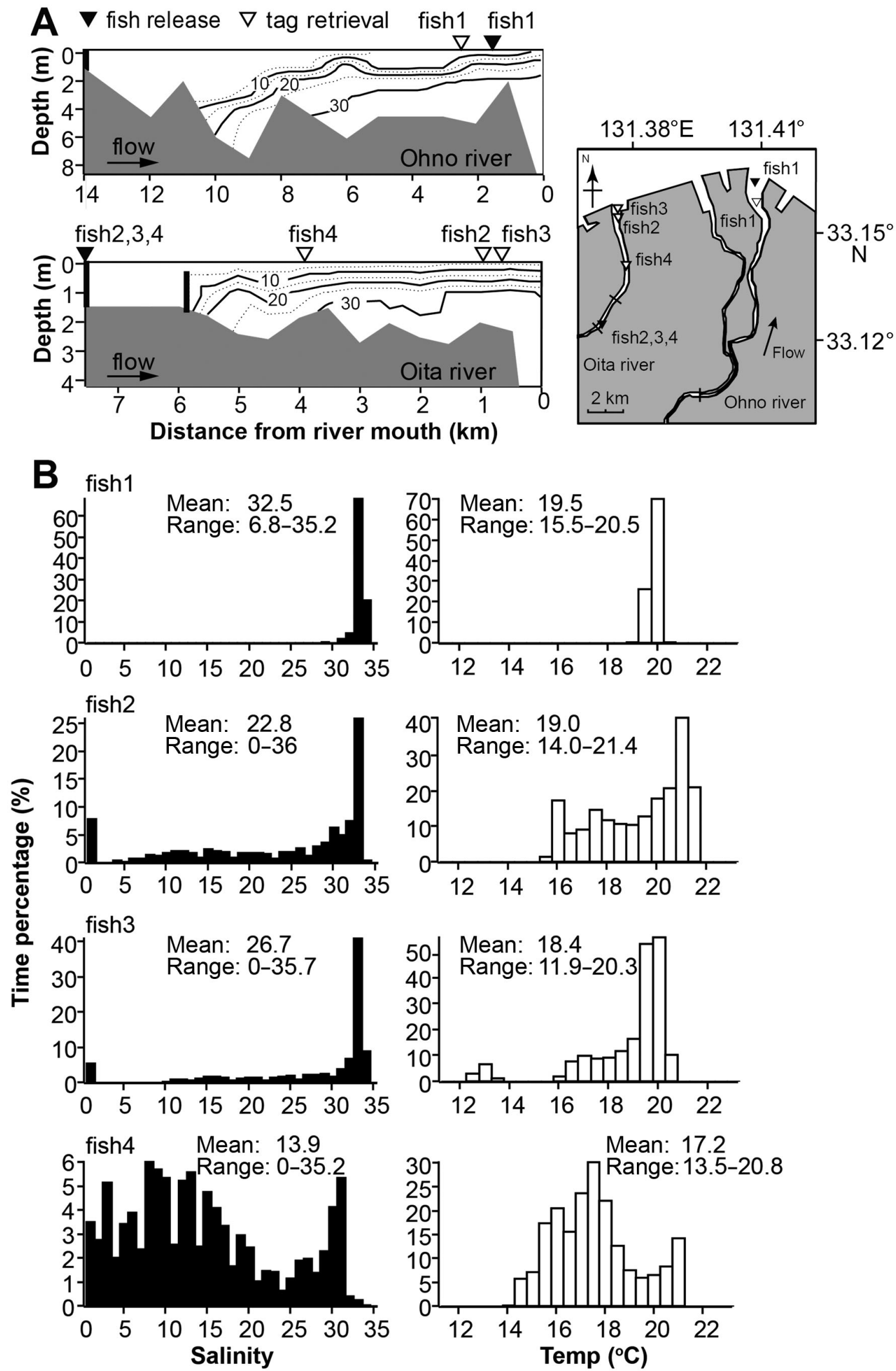

Fig. 6. Salinity at the study site and the water conditions that the fish experienced. (A) Contours represent salinity profiles measured by conventional CTD at the 2 study sites when the tide level was highest at spring tide. Black bars indicate groundsill. (B) Percentage of time spent by fish at a certain salinity and temperature as measured by fish-borne data loggers 


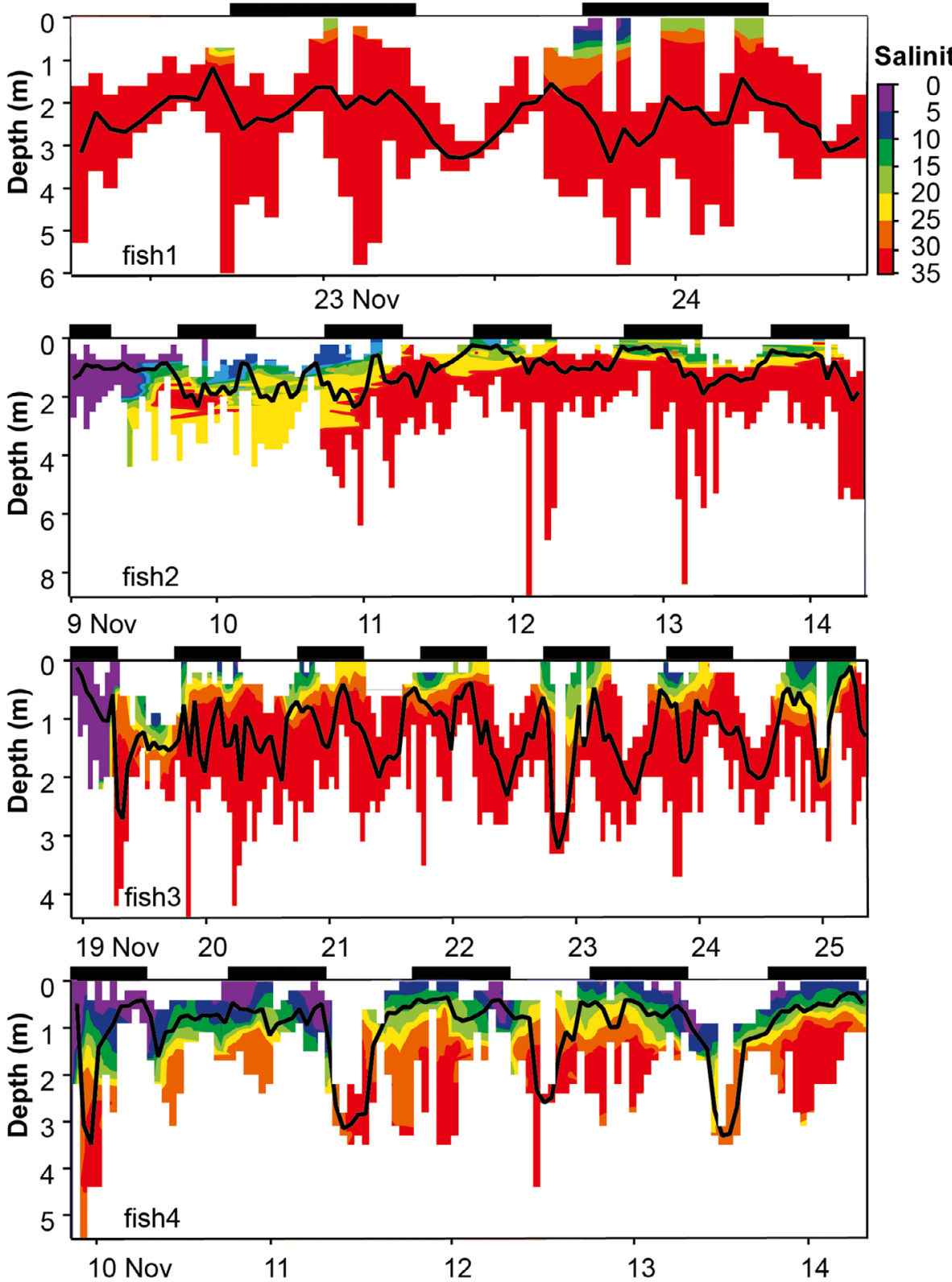

Fig. 7. Isohalines converted from the time series 'fish profiles' for the swimming activity of each fish. The salinity range is shown in different colors (see scale bar). The extent of the color bars depicts the range of the collected data for each time bin. Black lines represent the mean depth for each $1 \mathrm{~h}$ time bin. Black horizontal bars indicate night

resolve any inconsistencies in the main features of the water column (i.e. the depths and strength of thermo- and halocline) using the data logger. However, it should be noted that the accuracy of vertical profiles could be affected by fish swimming speed in the vertical direction and the amount of time fish remained at the same depth.

\section{Behavioral ecology of fish}

All fish showed a clear diel pattern; they often ascended to shallow, low-salinity water at night. Generally, there are 3 possible explanations for excursions from seawater to freshwater: predator avoidance, removal of ectoparasites, and foraging. Japanese sea bass are considered to be the largest predators at our study sites; therefore, it is unlikely that their purpose was predator avoidance. Heavily infested sea trout have been shown to return to freshwater prematurely (Birkeland 1996). Sea lice-infected Japanese sea bass have been observed in Tokyo Bay (T. Mori pers. obs.); however, no sea liceinfected fish were found in our study site in Oita Prefecture. Moreover, these short-term excursions were considered ineffective as a means of removing sea lice because sea lice can survive in freshwater for 1-2 wk (Finstad et al. 1995). A reasonable explanation for the night excursions seems to be that the

ured data (Daunt et al. 2003, Charrassin et al. 2004, Takahashi et al. 2008). The ORI400-DTC data logger also has a considerable time constant (15 s) on the temperature sensor (Table 1), which affects the salinity calculation. In this study, data averaging reduced the differences between profiles measured by data logger and conventional CTD. Despite a slight discrepancy in time and location, the 2 measurements yielded quite similar profiles, thus permitting us to sea bass were foraging on post-spawning Ayu fish Plecoglossus altivelis which spawn in October and November, when this research took place. The Ayu fish is one of the main prey species of Japanese sea bass (Ochiai \& Tanaka 1998) and has often been found in the stomach contents of sea bass in this season (N. Miyata pers. obs.). Ayu fish mainly spawn between 16:00 and 20:00 h in freshwater and die shortly after reproducing (Ochiai \& Tanaka 1998). Capturing 


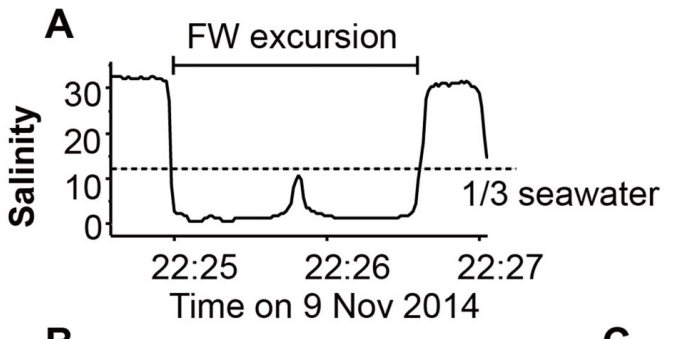

Fig. 8. (A) Duration of each freshwater (FW) excursion determined from raw salinity data $(\leq 12)$. (B-E) Bivariate histogram for each fish. Colors indicate frequency of FW excursions

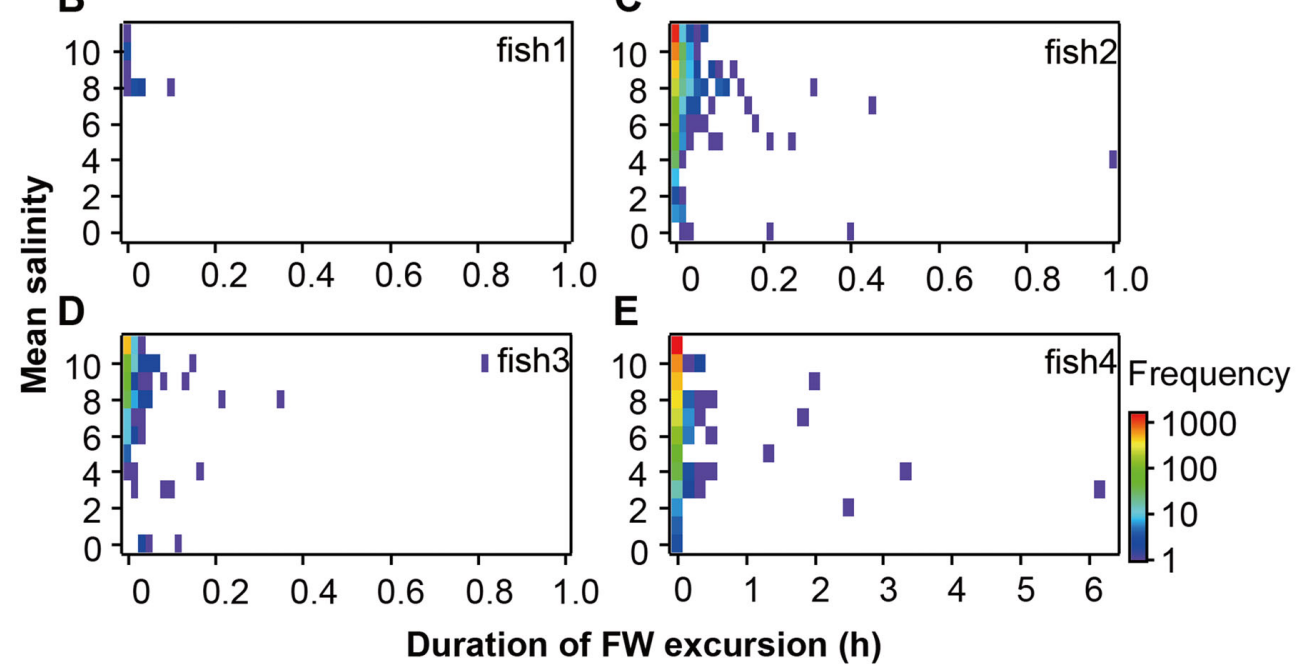

floating Ayu fish dying after spawning would be an efficient and energy-saving strategy for foraging sea bass.

Physiologically, teleost fish are known to maintain their osmotic concentration at about one-quarter to one-third of that in seawater (Schmidt-Nielsen 1997). Hence, Japanese sea bass in our field study were, on average, in a hyper-osmotic environment. This indicates a higher probability that their body-fluid osmoregulatory system would acclimate to seawater, even though 3 out of 4 fish were caught in a freshwater river (Fig. 6A). Their short-term excursions from seawater to freshwater might be an effective strategy for temporal utilization of hypo-osmotic environments without physiological and energetic cost; however, further insight into this aspect is a matter for future research.

In this study, we have demonstrated that the newly developed micro CTD data logger can be used to collect fine-scale salinity information from estuarinedependent fish with negligible measurement drift. Applying this method in future studies will give better insights into the habitat use, foraging strategies and osmoregulatory mechanisms of estuary-dependent species. This basic information about behavioral ecology of euryhaline fish is important to help understand estuarine ecosystems. Top-down forcing and trophic cascades often have pronounced effects on the abundance and species composition of autotrophs, leading to regime shifts and alternative states of ecosystems (Terborgh \& Estes 2010). Euryhaline fish can affect freshwater, estuarine and marine ecosystems through predation; hence, knowledge of their basic ecology is critical for the conservation of ecosystems around estuaries, which are some of the environments most vulnerable to anthropogenic change.

Acknowledgements. This study project was financially supported by the Bio-logging Science project, the University of Tokyo (UTBLS), a Sasakawa Scientific Research Grant (to T.M.) and the Japan Society for the Promotion of Science (24241001 and 25660152 to K.S.). We thank K. Utsumi and the staff of Oita Agriculture and Forestry Fisheries Study Instruction Center for their assistance. We also thank K. Kiyosue and T. Harada for catching experimental fish.

\section{LITERATURE CITED}

Birkeland K (1996) Consequences of premature return by sea trout (Salmo trutta) infested with the salmon louse (Lepeophtheirus salmonis Krøyer): migration, growth, and mortality. Can J Fish Aquat Sci 53:2808-2813

Biuw M, Boehme L, Guinet C, Hindell M and others (2007) Variations in behavior and condition of a Southern Ocean top predator in relation to in situ oceanographic conditions. Proc Natl Acad Sci USA 104:13705-13710

Boehme L, Meredith MP, Thorpe SE, Biuw M, Fedak M (2008a) Antarctic circumpolar current frontal system in the South Atlantic: monitoring using merge Argo and 
animal-borne sensor data. J Geophys Res 113:C09012, doi:10.1029/2007JC004647

Boehme L, Thorpe SE, Biuw M, Fedak M, Meredith MP (2008b) Monitoring Drake Passage with elephant seals: frontal structures and snapshots of transport. Limnol Oceanogr 53:2350-2360

Boehme L, Lovell P, Biuw M, Roquet F and others (2009) Technical note: Animal-borne CTD-satellite relay data loggers for real-time oceanographic data collection. Ocean Sci 5:685-695

Boesch DF (1977) A new look at the zonation of benthos along the estuarine gradient. In: Coull BC (ed) Ecology of marine benthos. University of South Carolina Press, Columbia, SC, p 245-266

Bœuf G, Payan P (2001) How should salinity influence fish growth? Comp Biochem Physiol C Toxicol Pharmacol 130:411-423

- Bulger AJ, Hayden BP, Monaco ME, Nelson DM, McCormick-Ray MG (1993) Biologically-based estuarine salinity zones derived from a multivariate analysis. Estuaries 16:311-322

- Charrassin JB, Park YH, Le Maho Y, Bost CA (2004) Fine resolution 3D temperature fields off Kerguelen from instrumented penguins. Deep-Sea Res I 51:2091-2103

Charrassin JB, Hindell M, Rintoul SR, Roquet F and others (2008) Southern Ocean frontal structure and sea-ice formation rates revealed by elephant seals. Proc Natl Acad Sci USA 105:11634-11639

Currin BM, Reed JP, Miller JM (1984) Growth, production, food consumption, and mortality of juvenile spot and croaker: a comparison of tidal and nontidal nursery areas. Estuaries 7:451-459

> Daunt F, Peters G, Scott B, Grémillet D, Wanless S (2003) Rapid-response recorders reveal interplay between marine physics and seabird behaviour. Mar Ecol Prog Ser 255:283-288

Elsdon TS, Gillanders BM (2003) Reconstructing migratory patterns of fish based on environmental influences on otolith chemistry. Rev Fish Biol Fish 13:217-235

Fedak M (2004) Marine animals as platforms for oceanographic sampling: a ' win/win ' situation for biology and operational oceanography. Mem Natl Inst Polar Res Spec Issue 58:133-147

Finstad B, Bjørn PA, Nilsen ST (1995) Survival of salmon lice, Lepeophtheirus salmonis Krøyer, on Arctic charr, Salvelinus alpinus (L.), in fresh water. Aquacult Res 26: 791-795

Gillanders BM (2005) Otolith chemistry to determine movements of diadromous and freshwater fish. Aquat Living Resour 18:291-300

> Hooker SK, Boyd IL (2003) Salinity sensors on seals: use of marine predators to carry CTD data loggers. Deep-Sea Res I 50:927-939

Kalish JM (1989) Otolith microchemistry: validation of the effects of physiology, age and environment on otolith composition. J Exp Mar Biol Ecol 132:151-178

Lankford TE, Targett TE (1994) Suitability of estuarine nursery zones for juvenile weakfish (Cynoscion regalis): effects of temperature and salinity on feeding, growth and survival. Mar Biol 119:611-620

> Lydersen C, Nost OA, Lovell P, McConnell BJ and others (2002) Salinity and temperature structure of a freezing Arctic fjord-monitored by white whales (Delphinapterus leucas). Geophys Res Lett 29:34-1-34-4, doi:10.1029/ 2002GL015462

Meredith MP, Nicholls KW, Renfrew IA, Boehme L, Biuw M, Fedak M (2011) Seasonal evolution of the upper-ocean adjacent to the South Orkney Islands, Southern Ocean: results from a 'lazy biological mooring'. Deep-Sea Res II 58:1569-1579

Ochiai A, Tanaka M (1998) Ichthyology (new version), Part 2. Koseishakoseikaku, Tokyo

Pinet PR (2011) Invitation to oceanography, 6th edn. Jones \& Bartlett, Burlington, MA

> Plaut I (1999) Effects of salinity acclimation on oxygen consumption in the freshwater blenny, Salaria fluviatilis, and the marine blenny, S. pavo. Mar Freshw Res 50:655-659

Reis-Santos P, Tanner SE, Elsdon TS, Cabral HN, Gillanders BM (2013) Effects of temperature, salinity and water composition on otolith elemental incorporation of Dicentrarchus labrax. J Exp Mar Biol Ecol 446:245-252

Roquet F, Park YH, Guinet C, Bailleul F, Charrassin JB (2009) Observations of the fawn trough current over the Kerguelen plateau from instrumented elephant seals. J Mar Syst 78:377-393

Schmidt-Nielsen K (1997) Animal physiology: adaptation and environment, 5th edn. Cambridge University Press, Cambridge

Shoji N, Sato K, Ozaki M (2002) Distribution and utilization of the stock. In: Tanaka M, Kinoshita I (eds) Temperate bass and biodiversity - new perspective for fisheries biology. Koseisha Koseikaku, Shinjuku, p 9-20

Sturlaugsson J, Sigmar G (1997) Tracking of Atlantic salmon (Salmo salar L.) and sea trout (Salmo trutta L.) with Icelandic data storage tags. In: Boehlert GW (ed) Application of acoustic tags and archival tags to assess estuarine, nearshore, and offshore habitat utilization and movement by salmonids. NOAA-TM NM. National Marine Fisheries Service, San Diego, CA, p 52-54

Takahashi A, Matsumoto K, Hunt GL, Shultz MT and others (2008) Thick-billed murres use different diving behaviors in mixed and stratified waters. Deep-Sea Res II 55: 1837-1845

Takei Y, Hiroi J, Takahashi H, Sakamoto T (2014) Diverse mechanisms for body fluid regulation in teleost fishes. Am J Physiol Regul Integr Comp Physiol 307:R778-R792

Tanaka M (1997) Inshore migration of coastal marine fish in relation to metamorphosis. Kaiyo Monthly 29:199-204

Terborgh J, Estes JA (eds) (2010) Trophic cascades: predators, prey, and the changing dynamics of nature. Island Press, Wachington, DC

Tseng YC, Hwang PP (2008) Some insights into energy metabolism for osmoregulation in fish. Comp Biochem Physiol C Toxicol Pharmacol 148:419-429

UNESCO (1981) Tenth report of the joint panel on oceanographic tables and standards. UNESCO Tech Pap Mar Sci 36:1-25

Watson DF, Merriam D (1992) Contouring: a guide to the analysis and display of spatial data. Pergamon Press, Oxford

- Weinstein MP, Weiss SL, Walters MF (1980) Multiple determinants of community structure in shallow marsh habitats, Cape Fear River estuary, North Carolina, USA. Mar Biol 58:227-243

Zydlewski J, Wilkie MP (2012) Freshwater to seawater transitions in migratory fishes. Fish Physiol 32:253-326 